Orihuela, P., Noel, M., Pacheco, S., Orihuela, J., Yaya, C., and Aguilar, R. (2019). "Application of Virtual and Augmented Reality Techniques During Design and Construction Process of Building Projects" In: Proc. $27^{\text {th }}$ Annual Conference of the International. Group for Lean Construction (IGLC), Pasquire C. and Hamzeh F.R. (ed.), Dublin, Ireland, pp. 1105-1116. DOI: https://doi.org/10.24928/2019/0220. Available at: <www.iglc.net>.

\title{
APPLICATION OF VIRTUAL AND AUGMENTED REALITY TECHNIQUES DURING DESIGN AND CONSTRUCTION PROCESS OF BUILDING PROJECTS
}

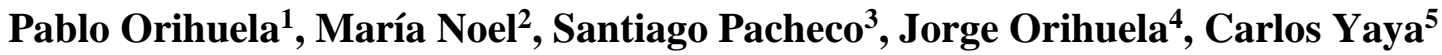 \\ and Rafael Aguilar ${ }^{6}$
}

\begin{abstract}
Research regarding Virtual Reality and Augmented Reality (VR/AR) as support tools of visual managment of design and construction for building projects has increased notably in recent years. However, most of these investigations present applications that improve the management of the project in a single phase or aspect, leaving aside the generation of value throughout the entire project. This article presents a brief review of the current state of VR / AR technologies, proposes the application of the Lean philosophy trough VR / AR applications in the different phases of the life cycle of a building project, and also shows several applications in real cases in which encouraging intial results were obtained. The proposed applications proved to be efficient to improve the communication between the different stakeholders, improving the understanding of the project, giving reliability to the decision making process, foreseeing errors, decreasing negative iterations and avoiding the time delays generated by the lack of an adequate visualization of the project. Finally, some recommendations about the nomenclature and standarization of the development level of the VR/AR applications are provided.
\end{abstract}

\section{KEYWORDS}

Virtual reality, augmented reality, visual management, value, waste

${ }^{1}$ General Manager Motiva S.A, Perú. Full Professor, Department of Engineering, Civil Engineering Section, Pontificia Universidad Católica del Perú PUCP, porihuela@ motiva.com.pe

${ }^{2}$ Lecturer, Department of Engineering, Civil Engineering Section, Pontificia Universidad Católica del Perú PUCP, mariaf.noel@ pucp.pe

${ }^{3}$ Civil Engineer, Motiva S.A., Perú, spacheco@ motiva.com.pe

${ }^{4}$ Architect, Motiva S.A., jorihuela@motiva.com.pe

${ }^{5}$ Research Assistant, VReal Research Laboratory, Civil Engineering Section, Pontificia Universidad Católica del Perú PUCP, c.yaya@pucp.pe

${ }^{6}$ Full Professor, Department of Engineering, Civil Engineering Section, Pontificia Universidad Católica del Perú PUCP, raguilar@pucp.pe 


\section{INTRODUCTION}

Traditionally, the design of the buildings has been represented in 2D drawings. This type of communication hinders the transmission of information among those involved during the different phases of construction projects, due to the additional work required to interpret plans or documents. The defects and re-works produced by the misinterpretation of plans and specifications during design and construction process can be avoided with the inclusion of technologies such as Virtual Reality and Augmented Reality as complementary tools to BIM models. These technologies improve the transmission of information between the design, supply and construction team, as well as communication between the project team and non-specialists stakeholders as investors and end users, allowing them to add more value during the design of the project.

\section{VIRTUAL AND AUGMENTED REALITY TECHNIQUES}

\section{VIRTUAL REALITY}

Virtual reality (VR) is defined as the virtual simulation of environments that allows the end user to interact in realistic three-dimensional simulations (Sherman and Craig, 2018). In simple terms, it is any artificial space generated by computer in which it is possible to live experiences that are not happening at that moment or in that place.

VR technology has advanced exponentially in recent years and is being applied in different industries to improve the productivity and competitiveness (Krasnov, 2018). In the fields of architecture, engineering and construction, VR is receiving considerable attention in recent years since allows to reduce project costs, delivery time, quality problems, among others.

The development of a VR experience for a building project involves processes of modeling the architectural proposal and generating the virtual environment. Figure 1 shows the complete process summarized in three stages and presents some of the most used software in each stage of the process, as well as the selection path according to their compatibility. In the first stage, CAD drawings are simplified to only schematic references. The most used software in this stage is AutoCAD. Once the simplified architectural information has been obtained, in the second stage the model is imported into a $3 \mathrm{D}$ modeling program, in which the architectural information is extruded (i.e. walls, columns, beams, among others). According to a survey conducted by Unreal Engine (Unreal Engine, 2018), the most used softwares for this stage are Archicad, Rhinoceros, Revit, 3ds Max and Sketchup. Also, in this stage, preliminary textures of the materials of the building project are defined and integrated into the model, resulting in a 3D model with textures. In the third stage, the preliminary 3D model is imported to the VR software and the location coordinates of the model are defined. Also, exterior views may be included in the model which are based on real environments captured by photos or videos, or imaginary environments simulated by computer. Then the model undergoes an optimization process in which the visual features are included to improve the user experience. This stage may include lighting configuration as well as the asssignment of specific properties to the textures of the materials such as relief, reflection, transparency, etc. In this stage the 
animations of objects and information windows that are required within the model are also defined. Among the most used softwares for the development of virtual environments are Unreal Engine and Unity that allow the construction of sophisticated experiences. The information in Figure 1 has been connected according to system (packages) of software families considering compatibility with the system design. The proper selection of software families is an indispensable process to avoid loss of information in all the process as well as to improve the effienciency of the VR/AR development process.

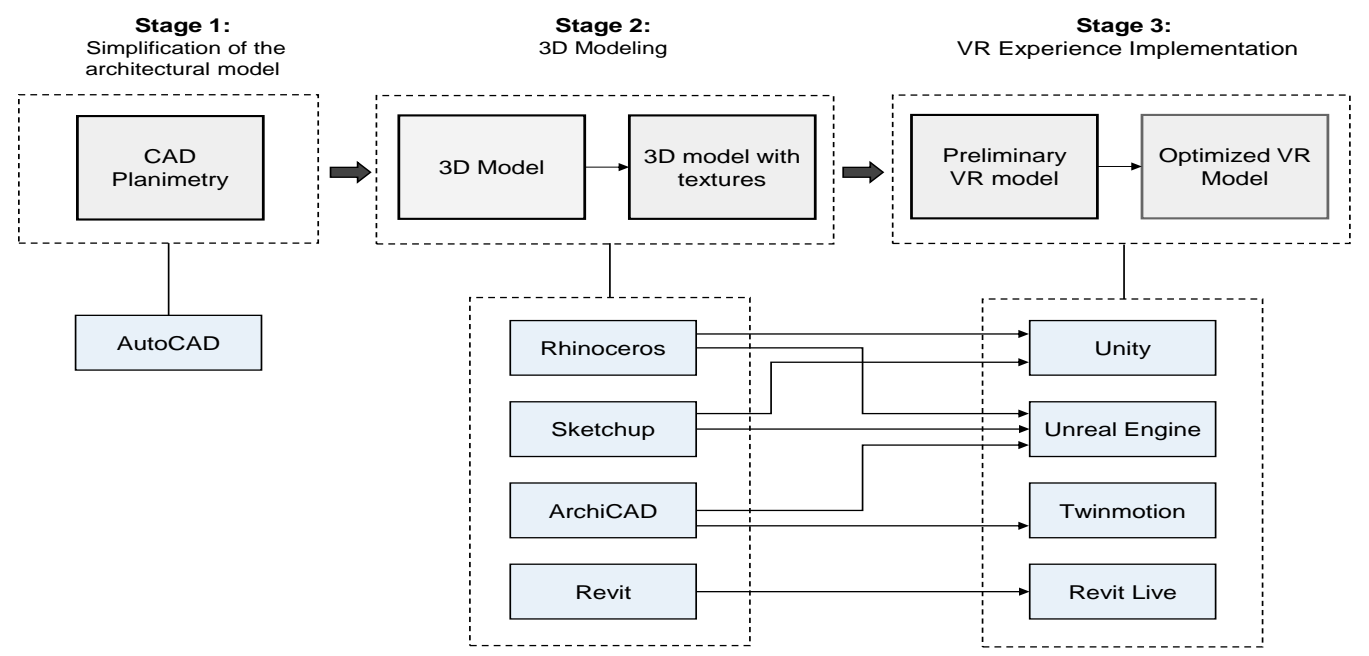

Figure 1. General outline of the implementation process of a building project using VR

\section{AUGMENTED REALITY}

Augmented Reality (AR) is a technique that enables users to interact with their physical environment through the overlay of digital information (Gruberte et al, 2017). AR can be considered a type of VR in which the real world is not replaced by a virtual one, the real world that the user observes is preserved and complemented with virtual information (Sherman and Craig, 2018). Currently, AR applications run on a wide range of devices, such as cell phones, tablets, PCs, or specific viewers for this function.

As shown in Figure 2, the developing process of a building project in AR presents three stages: the simplification of the architectural model, the 3D modeling and the development of the AR application. The first two stages are similar to those described in the generation of the VR experience. The third stage involves importing and processing the 3D model into an AR software and the creation of the AR application. Among the most popular and openaccess AR softwares are Unreal Engine 4 and Unity. The use of Software Development Kits (SDK) facilitates the generation of the applications according to the platform in which they are going to be executed (Android, iOS, Windows), since they serve as an interaction channel between the graphic engine and the device to use (Amin and Govilkar 2015). The different methods to project a digital object on the device screen are based on the recognition of a target. The target can be an image, a pattern or a pre-defined object. In the case of construction projects, the design (2D) drawings or scenes from the workplace are usually used. 


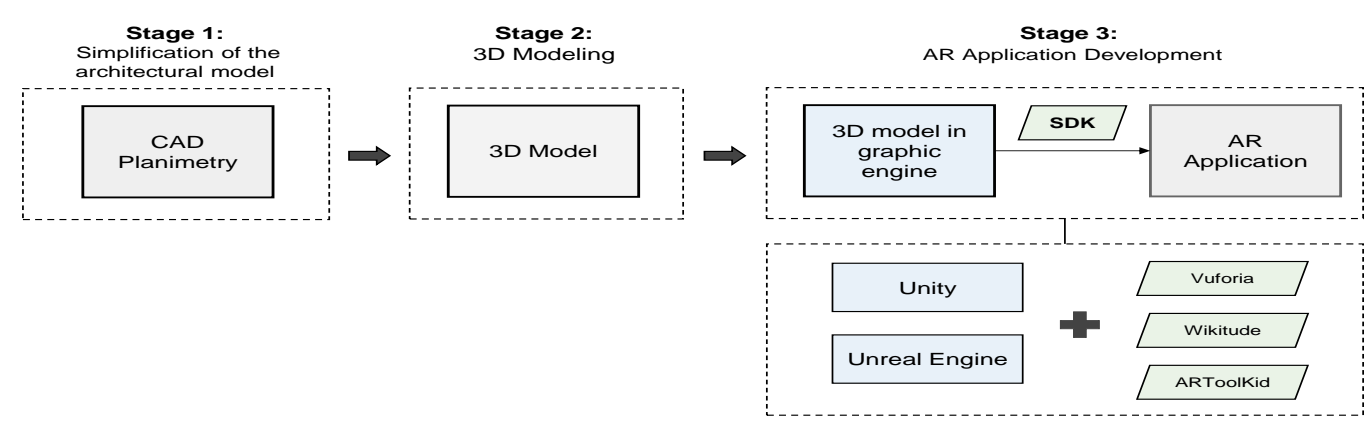

Figure 2. General outline of the implementing process of a building project using AR

\section{VR/AR IN CONSTRUCTION PROJECTS: REVIEW OF RECENT PUBLISHED LITERATURE}

In order to understand the current state of research related to VR / AR in the construction field, a thorough search was carried out in Scopus, Web of Science (WoS) and IGLC databases with the following terms: ("virtual reality" OR "augmented reality") AND construction AND building AND (LIMIT-TO (SRCTYPE, "p") OR LIMIT-TO (SRCTYPE, "j")). From this search, 498 results of articles in journals or conference proceedings were obtained, of which 494 are from the WoS and Scopus databases and 4 are from the IGLC procedures (one from 2005, one from 2012 and two from 2018). Analizing these results, a growing acceleration of scientific production was identified, in which published research in 2018 increased more than 100\% with respect to 2017 . With the aim of a more detailed analysis, the search was limited to publications from 2018 onwards. From this analysis, 59 occurrences were obtained which were classified as shown in Table 1.

Table 1. Classification of articles published from 2018 onwards on VR/AR in the construction industry

\begin{tabular}{cccc}
\hline Type & Description & $\begin{array}{c}\mathbf{N}^{\circ} \text { of Scopus } \\
\text { and WoS } \\
\text { articles }\end{array}$ & $\begin{array}{c}\mathbf{N}^{\circ} \text { of } \\
\text { IGLC } \\
\text { articles }\end{array}$ \\
\hline Technology & $\begin{array}{c}\text { Articles focusing on the development of } \\
\text { technological solutions and on the benefits of } \\
\text { applying VR / AR in the construction sector. } \\
\text { Application } \\
\text { Articles presenting one or more applications of } \\
\text { VR/AR technologies to the construction sector. } \\
\text { Review }\end{array}$ & 20 & 0 \\
& $\begin{array}{c}\text { Articles reviewing or criticizing publications on } \\
\text { VR / AR in the construction sector. }\end{array}$ & 43 & 2 \\
\hline
\end{tabular}

The WoS and Scopus articles classified by Application were further selected to identify the application areas with the most publications. The results presented in Table 2 were obtained from this classification. The results show that each of the articles reviewed fits into only one of the proposed classifications, which shows that the research currently carried out focuses on only one type of application of the VR/AR technologies to the 
construction and commercialization sector. The integral application of VR/AR throughout the phases of Lean Project Delivery System (LPDS): Project Definition, Lean Design, Lean Supply, Lean Assembly and Use, contributes to generate value and reduce losses during the development of a construction project, which coincides with the philosophy of Lean Construction.

Table 2. Classification of articles of VR/AR Application to the construction industry

\begin{tabular}{cc}
\hline Classification & № of articles \\
\hline Control of advance / Cost / Quality in construction project & 7 \\
Education & 6 \\
Design Review & 5 \\
Facility Management & 4 \\
Budget / Planning & 3 \\
Assignment of tasks in construction project & 3 \\
Others & 5 \\
\hline
\end{tabular}

\section{VR/AR APPLICATIONS DURING LPDS PHASES}

Some RV / RA applications were carried out in four building projects, each of the projects presenting at least one of the 5 phases of LPDS. These applications were tested, having an initial approval validation of the people involved.

\section{During Project Definition PhaSe}

The Project Definition phase involves understanding and aligning the purposes of the stakeholders, especially those of the project owners and end users. In the Project Definition phase some constraints are evaluated such as site conditions, rules and regulations in order to propose the Design Concepts, which then are presented to the owner of the project (Ballard, 2008).

In the first round of meetings, the design concepts are presented which implies showing the minimum data necessary to obtain a first estimation of the economic and financial feasibility of the project, so that the project owner can validate their financial expectations. This evaluation requires defining the metrics that allow calculating the construction costs and the income from the sale of the product. Moreover, at this stage the project owner needs to understand the architectural volumetry of the design concept, in addition to the financial figures. Although pencil and paper drawings probably continue to be useful tools for presenting design concepts alternatives, virtual 3D models may play an important role (Ballard, 2008). AR can facilitate the process of understanding and visualizing using simple technological devices.

In this line, to evaluate the potential of these technologies at the definition stage, AR was used in a building project. Figure 3 shows the application of AR using a smartphone for the visualization of areas and volumes. The 2D plan drawings of the design proposal zoned by uses and costs were shown to the owner of this project. Then, the same design proposal was shown to owner using AR (Figure 3a), with an interactive color menu, which allows to turn on and off the different zoned volumes, using the 2D location plan as a target (Figure 3b). The owner of this project stated that the visualization of the project with AR was more complete, more reliable and that it would help to present the project to the other 
investors, who are generally not architects or engineers and therefore have limited knowledge for an adequate visualization of the projects.

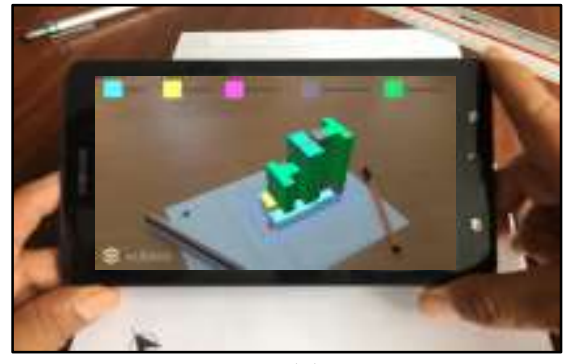

(a)

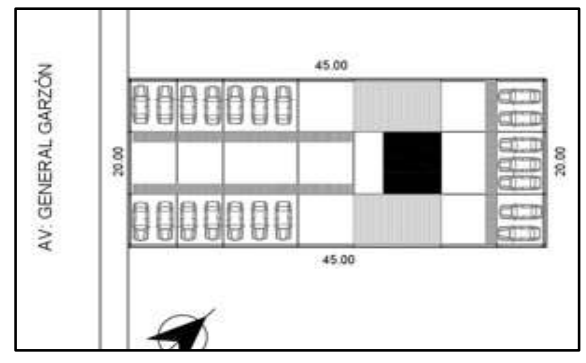

(b)

Figure 3. Application of AR to evaluate a design concept: (a) volumetric model in Augmented Reality, (b) 2D plane as target.

\section{DURING LEAN DESIGN PHASE}

During design development, the approval of the project owner and end user is crucial. This approval is mainly based on the final architectural proposal and thus, the correct visualization of the spaces during the development of the project allow to corroborate the design with the owner and the end-user, generating value and avoiding the frequent timedelays and losses due to innecesary rework and negative iterations.

Figure $4 \mathrm{a}$ and $4 \mathrm{~b}$ show the indoor common areas (lobby) in VR and the outdoor common areas (roof) in AR of a construction project in the design phase. For the development of the virtual models, the VR/AR development team interacted with the owner and the architecture and structural design team to acquiere information regarding the use of the spaces. The architect of this project mentioned that the VR/AR helped to confirm the proper dimensioning of the spaces, as well as to complete the textures and colors of the materials. The structural engineer mentioned that even though he knew the project, the VR improved his visualization. The owner was the one who benefited the most since the VR visualization helped him to have more security to approve the project.

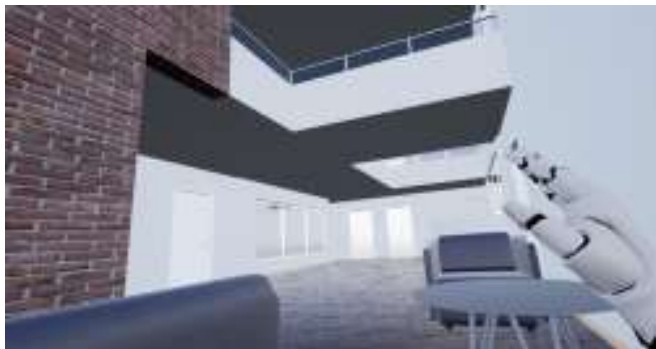

(a)

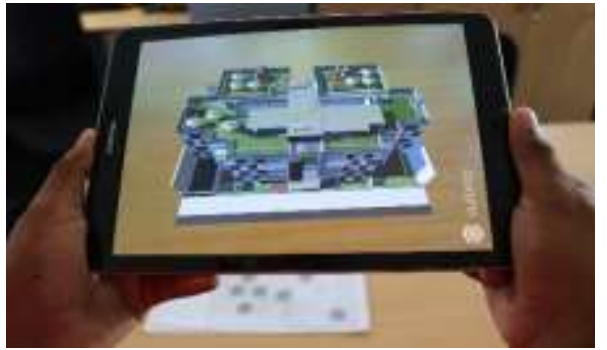

(b)

Figure 4. VR/AR visualization during the design process a) Visualization of interior spaces with VR b) Visualization of exterior spaces with AR

\section{EVALUATION OF USER SATISFACTION DURING LEAN DESIGN PHASE}

End user satisfaction can be validated when the design is finished. Figure 5a shows the implementation of VR of the interior of an apartment. For this, a drone was used (Figure 
5b) to obtain $360^{\circ}$ photographs of the urban surroundings at different heights according to the floor levels of the buildings. As shown, this experience allowed the end-user to observe the details and textures that the apartment will include. The end-user can also approach to the windows and balcony and observe the exterior scenery that the apartment will have in real life from the height that is located (Figure 5c). The experience also allows the user to interact with doors, lights and objects, as well as shows videos on the TV screen.

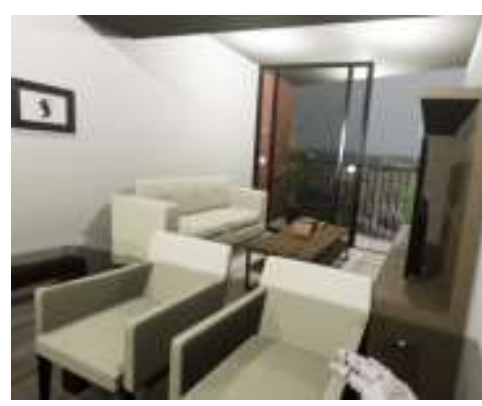

(a)

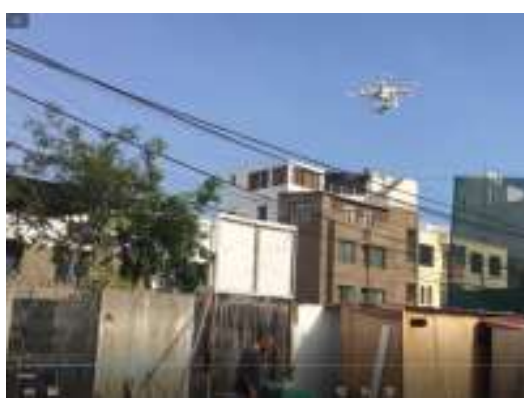

(b)

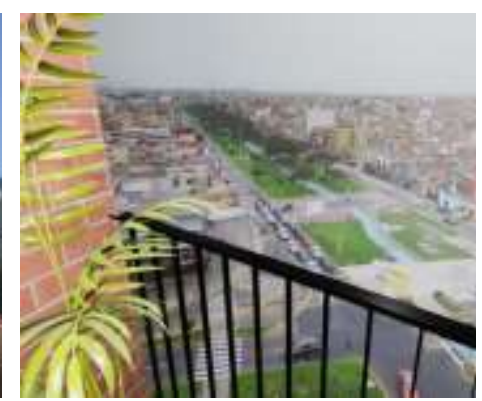

(c)

Figure 5. a) VR Department view b) Use of the drone to obtain $360^{\circ}$ photographs c) Incorporation of the $360^{\circ}$ photograph inside the model

The use of VR adds the experience of the end-user as an input for design, being an innovative approach that goes beyond the traditional resources such as the experience of the designer and the corresponding regulations (Ventura et al, 2018). These evaluations can be done interactively during the design process and also after completion, both to validate the quality of the design before the construction, and to support real estate presales with less cost compared to a pilot apartment. Figure 7 shows the results of a survey of 20 potential buyers of an apartment, during a real state fair. The results evidence that VR significantly improved the end-user experience regaring the proper visualization and understanding of the project.
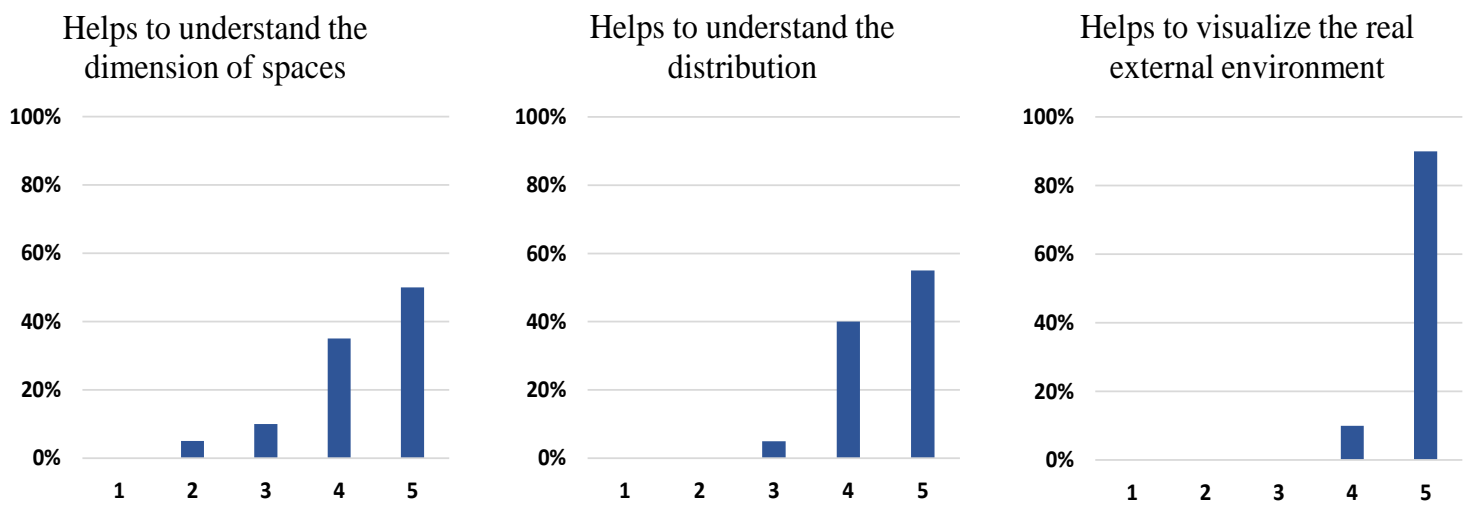

Figure 7. Results of the interview with potential end-users (20 people interviewed)

The end-user satisfaction is determined by three aspects: a) the location in the city, b) the urban environment and c) the building features (Orihuela and Orihuela, 2014). If the designers of housing programs could count on this verification in earlier stages of the project, the adjustments could be made according to reality and with the requirements of 
the buyers, avoiding future problems (Silva et al, 2019). For the evaluation of the third aspect referring to the building features, there are 15 attributes valued by end users. The most appreciated attributes apart from safety are architectural distribution, lighting and internal and external visual comfort (Orihuela and Orihuela, 2014) (Silva et al, 2018). These attributes can be measured effectively using Virtual Reality.

Another advantage is the possibility of showing a pilot apartment at any time and place as opposed to a real models that needs a fixed space and constant maintainance. It also offers some technical advantages such as showing an outside view, offering the buyer a safer purchase decision.

\section{DURING LEAN SUPPLY AND LEAN ASSEMBLY PHASE}

In the Supply phase, VR model is useful for visualizing the information contained in the detailed drawings, especially in the areas of services and kitchens and also in the finishing specifications, which is used for budgeting and purchasing issues. Figure 8 a shows an VR application that displays a windows with the specifications of some finishes which are activated when the handle is positioned over the objects.

During the Construction phase, the Weekly Schedule as a part of the Last Planner System, specifies the tasks that have been released from their restrictions and that must be executed day by day, so their communication to the last planners must be very effective and friendly (Orihuela et al, 2015). Figure 5b shows an application of AR, where the target is constituted by an A4 sheet with the plant of the level under construction and the crew leaders or any worker with a cell phone can select any of the 6 days of the week and see which are the work fronts and the tasks that have to be delivered at the end of each day.

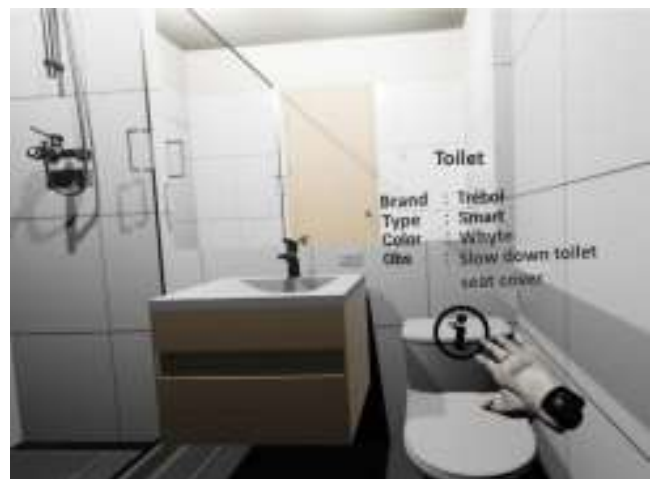

(a)

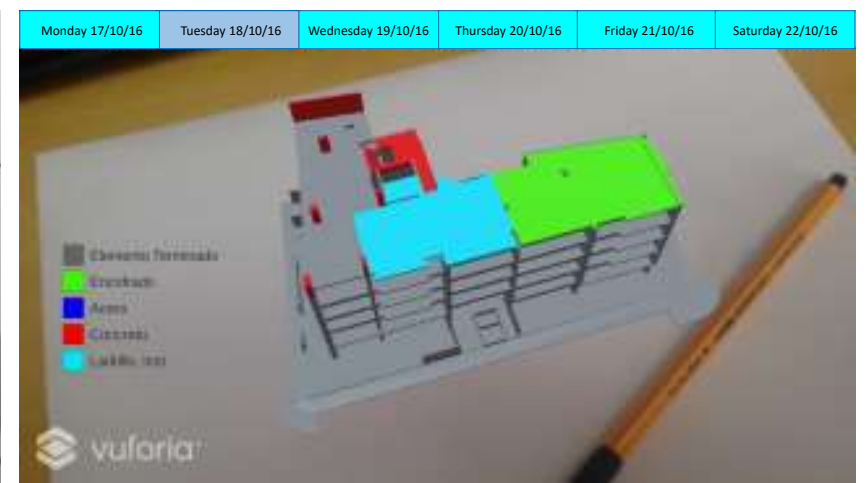

(b)

Figure 8. VR/AR applications (a) VR to visualize specifications during the supply (b) AR to visualize the weekly work plan during construction

\section{LEAN PRINCIPLES AND VR/AR APPLICATION BENEFITS}

Table 3 shows a correlational matrix between the Lean Constructions Principles (Sacks et al., 2010) and the 5 phases of the LPDS, in which the VR/AR proposed applications are 
placed. The evaluation of other applications is an ongoing study. In future research work, the matrix could be completed.

Table 3. Interaction of the Lean Principles and the phases of the project with the VR / AR applications

\begin{tabular}{|c|c|c|c|c|c|}
\hline Lean Principles & $\begin{array}{l}\text { Project } \\
\text { Definition }\end{array}$ & $\begin{array}{l}\text { Lean } \\
\text { Design }\end{array}$ & $\begin{array}{l}\text { Lean } \\
\text { Supply }\end{array}$ & $\begin{array}{l}\text { Lean } \\
\text { Assembly }\end{array}$ & Use \\
\hline \multicolumn{6}{|l|}{ Reduce variability } \\
\hline \multicolumn{6}{|l|}{ Reduce cycle times } \\
\hline \multicolumn{6}{|l|}{ Reduce batch sizes } \\
\hline Increase flexibility & $\sqrt{ }$ & $\sqrt{ }$ & & & \\
\hline \multicolumn{6}{|l|}{$\begin{array}{l}\text { Select an appropriete production control } \\
\text { approach } \\
\text { Standardize }\end{array}$} \\
\hline Institute continuous improvement & $\sqrt{ }$ & $\sqrt{ }$ & $\sqrt{ }$ & $\sqrt{ }$ & \\
\hline Use visual management & $\sqrt{ }$ & $\sqrt{ }$ & $\sqrt{ }$ & $\sqrt{ }$ & \\
\hline $\begin{array}{l}\text { Design the production system for flow and } \\
\text { value }\end{array}$ & & & & $\sqrt{ }$ & \\
\hline $\begin{array}{l}\text { Ensure comprehensive requirements } \\
\text { capture }\end{array}$ & $\sqrt{ }$ & $\sqrt{ }$ & $\sqrt{ }$ & $\sqrt{ }$ & \\
\hline Focus on concept selection & $\sqrt{ }$ & $\sqrt{ }$ & & & \\
\hline Ensure requirements flow down & & $\sqrt{ }$ & $\sqrt{ }$ & & \\
\hline Verify and validate & $\sqrt{ }$ & $\sqrt{ }$ & & & \\
\hline \multicolumn{6}{|l|}{ Go and see yourself } \\
\hline Decide by consensus, consider all options & $\sqrt{ }$ & $\sqrt{ }$ & $\sqrt{ }$ & $\sqrt{ }$ & \\
\hline Cultivate an extended network of partners & & & & & \\
\hline
\end{tabular}

During the Project Definition phase, the visualization of the volumes of the design concepts improves the communication between the project owner and the architect, which allows a quick validation of the design concepts. With these results, the principles in the matrix are checked.

During Lean Design phase, the visualization of the complete volume and the interior and exteriors spaces, allows to improve the communication inside, the design team and, between this team and the project owner. Also it allows having feedback from the potential users, other designers and the project owner. In more advanced stages of the design, these technoclogies may also allow evaluating the satisfaction of the potential clients.

In the Lean Supply phase, VR / AR technologies assist in the transmission of design information to the responsible supply team. In this way, the total understanding of the requirements and the acceleration and improvement of the quality of the budget and the offer is ensured.

Also, during the Lean Assembly phase, these technologies allows to understand the project and to comprehend the details of the design that influences the construction process, avoiding delays and additional work during construction. The AR allows to communicate 
in a visual way the scheduling of the building site to the ones involved in the project and to better understand the work to be done.

\section{RECOMMENDATIONS}

From the review of the existing literature, it has been noted that the different authors do not use a standardized nomenclature to refer to the different visualization techniques. For example, the term VR is sometimes used to refer to any interaction with a 3D model, without differentiating it from the immersive VR. For this reason, it is necessary to create a glossary that standardizes the terms related to VR/AR aiming at facilitating the communication and diffusion of these techniques between researchers, designers, constructors and project owners. The authors propose the use of the concept of Levels of Detail (LoD) for dealing with VR or AR techniques in construction projects. Table 3 presents a summary of this proposal.

Table 3. Levels of Development (LoD) in Virtual or Augmented Reality projects

\begin{tabular}{cl}
\hline LoDs & \multicolumn{1}{c}{ Description } \\
\hline LoD 100 & $\begin{array}{l}\text { Basic level of visual information, such as areas, heights, volumes, location and } \\
\text { orientation, applicable to interior and exterior spaces. }\end{array}$ \\
LoD 200 & $\begin{array}{l}\text { Same as LoD } 100 \text { but including textures, lighting, reflection and transparency. } \\
\text { LoD } 300\end{array}$ \\
$\begin{array}{l}\text { Same as LoD 200, but includes other elements that improve the interaction with } \\
\text { virtual reality (e.g. turn on and off lights, open doors, open taps and move objects). }\end{array}$ \\
\hline
\end{tabular}

\section{CONCLUSIONS}

The combination of VR and AR for the visualization of building projects, during their different phases of the life cycle, contribute significantly to avoid waste and to generate value. Its use in each of the project phases and in early stages can provide transparency and reliability in the decision making of those involved, avoiding future problems, such as negative iterations, waste, delays and rework. The use of each technique depends on the context in which it is to be applied. For desktop works such as the Project Definition phase and the initial part of the Design phase, VR is totally applicable. However, for field work such as the Construction phase, AR can be applied as its use only requires a target and a Smartphone or Tablet. The sudden increase in research into these new technologies, demonstrate that their application will radically change the traditional forms of visual management of building projects; the research in this area will certainly contribute to the development of the construction sector.

\section{ACKNOWLEDGMENTS}

This research was performed by Vreal Laboratory at PUCP and Motiva company. The authors acknowledge the funding provided by DGI-PUCP in the framework of the project $\mathrm{N}^{\mathrm{o}}$ 2018-601. The authors also acknowledge the special support provided by Yamile Rojo and Christian Yaranga for the the implementation of the VR/AR experiences. 


\section{REFERENCES}

Amin D., Govilkar S. (2015) Comparative Study of Augmented Reality SDK's, University of Mumbai, PIIT, New Panvel, India.

Ballard, G. (2008). Lean Project Delivery System: An Update. Lean Construction Journal, pp 1-19.

Chesnut C., Rudolph S. (2010) Augmented Reality Method and System for designing environments and buying/selling goods. U.S. Patent No 8,606,657, 10 Dic. 2013.

Grubert, J., Langlotz, T., Zollmann, S., Regenbrecht, H. (2017). Towards pervasive augmented reality: Context-awareness in augmented reality. IEEE transactions on visualization and computer graphics, Vol 23(6), pp 1706-1724.

Krasnov, M. (2018). Using Virtual Reality and 360-degree Photos and Videos in Marketing. Master's Thesis. Haaga-Helia University of Applied Science, Helsinki, Finland. Orihuela, P., Orihuela, J. (2014). Needs, values and post-occupancy evaluation of housing project customer: A pragmatic view. Procedia Engineering Volume 85, 2014, pages 412-419.

Orihuela, P., Canchaya, L., Rodriguez, E. (2015). Gestión Visual del Sistema Last Planner mediante el modelado BIM. SIBRAGEC - ELAGEC 2015, Sao Carlos, Brasil.

Sherman, W., Craig, A. (2018). Understanding virtual reality: Interface, application, and design, Indiana, United States. Morgan Kaufmann. ISBN 978-0-12-818399-1

Silva, D., Ferreira, L., Melo, L., Silva, C., Oliveira, A. (2018). Systematic Literature Review: Customer's Requirements for Social Housing Design. Proceedings of International Conference for Sustainable Design of the Built Environment-SDBE London. Pages $355-365$.

Unreal Engine (2018). Using unreal studio to get epic results with rhino $3 \mathrm{~d}$ files in unreal engine. Available online at https://www.youtube.com/watch? $\mathrm{v}=7 \mathrm{kFYZ4ZBr8g}$ Accessed date: February 2018.

Ventura, S. M., Hilfert, T., Archetti, M., Rizzi, M., Spezia, A., Tagliabue, L. C., Oliveri, E., Ciribini, A. L. (2018). Evaluation of building use scenarios by crowd simulations and immersive virtual environments: a case study. In ISARC. In: Proceedings of the International Symposium on Automation and Robotics in Construction, vol. 35, pp. 18. IAARC Publications.

Wang, S., Mao, Z., Zeng, C., Gong, H., Li, S., Chen, B. (2010). A new method of virtual reality based on Unity3D. In Geoinformatics, 2010 18th International Conference on, pp 1-5. 
Orihuela, P., Noel, M., Pacheco, S., Orihuela, J., Yaya, C., and Aguilar, $R$ 